\title{
TOXICIDADE DIFERENCIAL DE PRODUTOS À BASE DE ABAMECTINA AO ÁCARO Brevipalpus phoenicis (Geijskes, 1939) (ACARI: TENUIPALPIDAE) EM CITROS ${ }^{1}$
}

\author{
DANIEL JÚNIOR DE ANDRADE², CARLOS AMADEU LEITE DE OLIVEIRA³, \\ NATALI CALAZANÇA DOS SANTOS ${ }^{4}$, MATHEUS ROVERE DE MORAIS ${ }^{5}$
}

RESUMO- O ácaro Brevipalpus phoenicis é uma das principais pragas dos citros por ser vetor do "Citrus Leprosis Virus” (CiLV), agente causal da leprose, uma das mais graves doenças da citricultura. Objetivou-se avaliar o efeito tóxico de produtos à base de abamectina sobre o ácaro B. phoenicis. Foram realizados um experimento de ação direta e três de ação residual no Laboratório de Acarologia do Departamento de Proteção de Plantas (Fitossanidade) da FCAV - UNESP, Jaboticabal-SP. O delineamento adotado nos bioensaios foi o inteiramente casualizado, onde 10 tratamentos foram repetidos 7 vezes, sendo cada repetição composta por um fruto de laranja. Os tratamentos estudados (mL p.c./100 L de água) foram: Acaramik a 20; $30 ; 40$ e $50 \mathrm{~mL}$; Vertimec a 30 e $40 \mathrm{~mL}$; Abamectin Nortox a 30 e $40 \mathrm{~mL}$; Tricofol a $77 \mathrm{~mL}$ e uma testemunha sem aplicação. Utilizaram-se frutos com presença de verrugose, que foram lavados e parcialmente parafinados, deixando-se uma área sem parafina, que foi circundada com cola entomológica para contenção dos ácaros. Transferiram-se 20 ácaros adultos B. phoenicis para cada fruto. No bioensaio de ação direta, a transferência foi realizada antes das aplicações e, nos bioensaios de ação residual, aos 5; 10 e 15 dias após a aplicação dos produtos. A aplicação dos produtos sobre os frutos foi realizada em Torre de Potter. Os resultados obtidos nos bioensaios evidenciaram que os melhores tratamentos foram: Tricofol a $77 \mathrm{~mL}$, Acaramik a 40 e 50 mL e Vertimec a $40 \mathrm{~mL}$. De forma geral, os produtos testados podem ser utilizados no controle do ácaro $B$. phoenicis.

Termos para indexação: Leprose dos citros, Controle químico, Manejo Integrado de Pragas.

\section{DIFFERENTIAL TOXICITY OF ABAMECTIN BASED PRODUCTS OVER Brevipalpus phoenicis (Geijskes, 1939) (ACARI: Tenuipalpidae) MITE IN CITRUS}

\begin{abstract}
The mite Brevipalpus phoenicis (Geijskes, 1939) (Acari: Tenuipalpidae) is one of the most important pests in Brazil citrus plantation, because it is the virus “Citrus Leprosis Virus" (CiLV) vector, one of the most serious citrus plantation diseases. The purpose of this experiment was to evaluate the toxical effect of abamectin in the mite $B$. phoenicis. It was performed one direct action and three persistence action bioassays at the Acarology Laboratory from the Department of Plant Protection of FCAV/UNESP, in Jaboticabal, São Paulo state. In the bioassays it was used the completely randomized design, with 10 treatments repeated 7 times, and each sample composed by one orange fruit. The treatments performed (mL c.p./100 L) were: Acaramik at 20, 30, 40 and $50 \mathrm{~mL}$; Vertimec at 30 and $40 \mathrm{~mL}$; Abamectin Nortox at 30 and 40 $\mathrm{mL}$; Tricofol at $77 \mathrm{~mL}$ and a control without application. It was used fruits with citrus scab. The fruits were washed and partially covered with paraffin, keeping a circular area over the top without being covered, which was surrounded with entomological glue for containing mites on it. It was transferred to each fruit 20 adult mites $B$. phoenicis. In the direct action bioassay, the transfer was made before product applications and, in the persistence action bioassays, at 5, 10 and 15 days after the product's application. The product's application over the fruits was performed by using the Potter Tower. This experiment demonstrated that the most efficient treatments were: Tricofol at $77 \mathrm{~mL}$, Acaramik at 40 and $50 \mathrm{~mL}$ and Vertimec at $40 \mathrm{~mL}$. Generally, the tested products can be used to control B. phoenicis.
\end{abstract}

Index terms: Citrus leprosis, Chemical control, Integrated Pest Management.

${ }^{1}$ (Trabalho 046-09). Recebido em: 17-02-2009. Aceito para publicação em: 23-10-2009.

${ }^{2}$ Eng $^{\circ}$ Agrônomo, Mestrando em Entomologia Agrícola, Departamento de Fitossanidade, FCAV/UNESP, via de acesso Prof. Paulo Donato Castellane, s/n - CEP: 14874-900, Jaboticabal - SP, e-mail: danieldwv@yahoo.com.br.

${ }^{3}$ Eng $^{\circ}$ Agrônomo, Prof. Titular, Departamento de Fitossanidade, FCAV/UNESP, via de acesso Prof. Paulo Donato Castellane, s/n CEP: 14874-900, Jaboticabal - SP, e-mail: amadeu@fcav.unesp.br.

${ }^{4}$ Graduanda em Agronomia, Departamento de Fitossanidade, FCAV/UNESP, via de acesso Prof. Paulo Donato Castellane, s/n - CEP: 14874-900, Jaboticabal - SP, e-mail: natali.00@hotmail.com.

${ }^{5}$ Graduando em Ciências Biológicas, Departamento de Fitossanidade, FCAV/UNESP, via de acesso Prof. Paulo Donato Castellane, s/n - 14874-900, Jaboticabal - SP, e-mail: matheusdemorais@yahoo.com.br. 


\section{INTRODUÇÃO}

O ácaro Brevipalpus phoenicis (Geijskes, 1939) (Acari: Tenuipalpidae) é uma das principais pragas da cultura dos citros no Brasil por ser o vetor do vírus da leprose dos citros (Citrus leprosis virus - CiLV), agente causal da leprose, que há várias décadas é citada como uma das mais graves doenças da citricultura devido aos sérios prejuízos que acarreta à produção (Oliveira, 1986; Rodrigues et al., 2001).

As plantas doentes têm a capacidade fotossintética reduzida, os ramos secam e há acentuada desfolha. Quando há incidência severa da doença, o pomar pode tornar-se economicamente inviável, dada a baixa produtividade e a redução no tamanho dos frutos, embora não afete a qualidade do suco (Chiavegato et al., 1982; Oliveira et al., 1991).

Segundo Alves (2000), para manejo do ácaro B. phoenicis, diversas pesquisas vêm sendo realizadas, dando-se ênfase aos aspectos bioecológicos do ácaro, métodos de amostragem da densidade populacional, preservação de inimigos naturais, tratos culturais e desenvolvimento de novas moléculas. Contudo, o controle químico ainda tem sido a principal tática de controle do ácaro da leprose.

$\mathrm{O}$ ingrediente ativo abamectina pertence ao grupo das avermectinas. É um composto derivado da fermentação natural da bactéria de solo Streptomyces avermitilis, sendo utilizado como inseticida, acaricida e nematicida. A abamectina age sobre os ácaros por contato e ingestão, possuindo a capacidade de interferir no sistema nervoso dos ácaros, atuando como ativador de canais de cloro (Gallo et al., 2002).

Reis et al. (2004) avaliaram o efeito da abamectina (Vertimec $18 \mathrm{CE}$ ) em condições de campo, no controle do $B$. phoenicis em cafeeiro e verificaram que o produto apresentou eficiência acima de $80 \%$ no controle de todas as fases pós-embrionárias do B. phoenicis. Franceschi et al. (2008) estudaram a eficácia e a praticabilidade agronômica da abamectina (Abamectin Nortox) acrescida de óleo vegetal no controle do ácaro B. phoenicis na cultura do café e observaram que todas as dosagens avaliadas apresentaram percentuais de controle semelhante ao tratamento-padrão cyhexatin.

Experimentos realizados em laboratório por Fernandes et al. (2008) constataram que populações de $B$. phoenicis procedentes de pomares de citros e lavouras de cafeeiro foram semelhantes em termos de mortalidade, frente à ação do acaricida abamectina.

Porém, é importante salientar que esses resultados podem variar de cultura para cultura, devido principalmente a fatores relacionados à arquitetura das plantas, ao comportamento do ácaro na planta e aos equipamentos de pulverização (Fernandes et al., 2008), bem como à formulação e ao produto comercial acaricida utilizado.

Portanto, o presente trabalho objetivou avaliar o efeito tóxico de diferentes produtos à base de abamectina ao ácaro B. phoenicis em citros.

\section{MATERIAL E MÉTODOS}

Os experimentos foram realizados no laboratório de Acarologia pertencente ao Departamento de Fitossanidade da Faculdade de Ciências Agrárias e Veterinárias, da Universidade Estadual Paulista (FCAV/UNESP), Câmpus de Jaboticabal-SP.

Foram coletados frutos de laranja da variedade 'Pera', com sintomas de leprose, infestados com B. phoenicis em pomar de citros da região de Jaboticabal, que não vinham sendo pulverizados com produtos fitossanitários para dar início à criaçãoestoque de ácaros da leprose. Escolheram-se frutos que, além dos sintomas de leprose, apresentassem sintomas de verrugose, pois o ácaro tem preferência por frutos com superfície irregular (Albuquerque et al., 1997). No laboratório, os frutos foram lavados com água corrente, secados à sombra e parcialmente parafinados, deixando-se uma área de aproximadamente $10 \mathrm{~cm}^{2}$ sem parafina, que foi circundada com cola adesiva (Tree Tanglefoot ${ }^{\circledR}$ ) para conter os ácaros.

Os frutos foram dispostos em bandejas plásticas e mantidos em câmara climatizada à temperatura de $25 \pm 1^{\circ} \mathrm{C}$, UR de $60 \pm 5 \%$ e fotofase de 14 horas. Quando necessário, os frutos em início de deterioração foram substituídos, e a transferência dos ácaros, realizada por meio do contato entre os dois frutos.

Foram realizados quatro experimentos, sendo um de ação direta e três de ação residual dos produtos sobre o ácaro B. phoenicis. Todos os produtos à base de abamectina utilizados no presente trabalho possuíam uma concentração de $18 \mathrm{~g}$ i.a/L de produto comercial.

O delineamento adotado nos experimentos foi o inteiramente casualizado, onde 10 tratamentos foram repetidos 7 vezes, sendo cada repetição composta por um fruto de laranja (Tabela 1). Os tratamentos estabelecidos foram constituídos dos produtos comerciais, expressos em $\mathrm{mL}$ por $100 \mathrm{~L}$ de água destilada: Acaramik a 20; 30; 40 e 50; Vertimec a 30 e 40; Abamectin Nortox a 30 e 40; Tricofol a 77 (tratamento-padrão) e uma testemunha com aplicação de água destilada sem acaricida.

Para a realização dos bioensaios, foram 
colhidos frutos de laranja da variedade 'Pera', com sintomas de verrugose, em um pomar pertencente à FCAV/UNESP, com vários meses sem pulverizações de produtos fitossanitários. Uma vez no laboratório, esses frutos receberam o mesmo processo de lavagem com água e parafinagem descrito no preparo dos frutos da criação-estoque. Porém, foi deixada nos frutos uma área menor $\left(5 \mathrm{~cm}^{2}\right)$ sem parafina, que foi circunda com cola adesiva (Tree Tanglefoot ${ }^{\circledR}$ ).

No experimento de ação direta dos produtos sobre o ácaro B. phoenicis, foram transferidos 20 ácaros adultos procedentes da criação-estoque para cada fruto de laranja, com auxílio de pincel de apenas um pelo e microscópio estereoscópico, e na sequência realizaram-se as pulverizações sobre os frutos (Experimento 1).

Da mesma forma, nos experimentos de efeito residual, foram transferidos 20 ácaros de B. phoenicis procedentes da criação-estoque para cada fruto. Contudo, a transferência dos ácaros foi realizada aos 5 (Experimento 2), 10 (Experimento 3) e 15 (Experimento 4) dias após a aplicação dos produtos sobre os frutos.

A pulverização foi realizada com um micropulverizador (Torre de Potter), calibrado a $5 \mathrm{lbf} /$ $\mathrm{pol}^{2}$, gastando-se $2 \mathrm{~mL}$ de calda por aplicação, o que equivale a aproximadamente 15 litros de calda por planta. Após as aplicações, os frutos foram mantidos em câmara climatizada às mesmas condições de temperatura, umidade relativa e fotofase citadas anteriormente.

Foram realizadas avaliações de mortalidade 1; 3; 5; 10 e 15 dias após a pulverização dos frutos no experimento de ação direta e 1; 3; 5; 10 e 15 dias após a transferência dos ácaros $B$. phoenicis nos experimentos de ação residual. Nas avaliações, foi quantificado o número de ácaros mortos, vivos e retidos na barreira adesiva de cola de cada parcela experimental.

Os dados relativos às contagens de ácaros foram transformados em $\ln (x+5)$, com o objetivo de normalizar os dados a serem analisados pelo teste F. As médias foram comparadas pelo teste de Tukey, a 5\% de probabilidade. A redução real ou a eficiência foi calculada pela fórmula de Abbott (1925), tomando-se por base a população de ácaros vivos de cada tratamento e transformados em porcentagem de mortalidade.

\section{RESULTADOS E DISCUSSÃO}

Na avaliação realizada 1 dia após a aplicação, todos os tratamentos diferiram estatisticamente da testemunha, porém Acaramik a 40 e 50 mL, Vertimec a 30 e $40 \mathrm{~mL}$, Abamectin Nortox e Tricofol, com percentuais de mortalidade que variaram de 92,3 a $100 \%$, diferiram do Acaramik a 20 e $30 \mathrm{~mL}$, com percentuais de redução de 62 a $68 \%$, respectivamente (Tabela 1). Verificou-se mortalidade semelhante entre os tratamentos com abamectina e o padrão Tricofol (77 mL p.c/ 100 L de água), com exceção do Acaramik a 20 e $30 \mathrm{~mL}$.

Após 1 dia da aplicação, os tratamentos Acaramik a $50 \mathrm{~mL}$, Vertimec a 30 e $40 \mathrm{~mL}$, Abamectin Nortox a $30 \mathrm{~mL}$ e Tricofol causaram mortalidade de $100 \%$, evidenciando excelente efeito de choque desses produtos sobre $B$. phoenicis nas dosagens testadas. Observou-se que, com o passar do tempo, os percentuais de mortalidade aumentaram gradativamente, atingindo $100 \%$ de controle aos 15 dias após a aplicação, em todos os tratamentos.

Na avaliação realizada aos 3 dias após a aplicação, todos os tratamentos diferiram da testemunha, mas não entre si, com percentuais de mortalidade que variaram de 86 a 100\%, com exceção do Acaramik a $20 \mathrm{~mL}$ (65\%). Aos 5 dias da aplicação, todos os tratamentos diferiram da testemunha, apresentando percentuais de mortalidade que variaram de 76 a 100\%. Nas avaliações realizadas aos 10 dias após a aplicação, todos os tratamentos mostraram eficiência semelhante sobre o ácaro B. phoenicis e diferiram estatisticamente da testemunha, mas não entre si, com percentuais de mortalidade que variaram de 99 a $100 \%$.

Fernandes et al. (2008) avaliaram a eficiência de acaricida abamectina (Vertimec $18 \mathrm{CE}$ ) aplicado diretamente sobre $B$. phoenicis, na dosagem de $40 \mathrm{~mL}$ de p.c./100 L de água, em laboratório, e observaram mortalidades médias de 43\%, 2 horas após a aplicação, e de 71\%, 24 horas após a aplicação. Os resultados obtidos por estes autores foram inferiores aos obtidos no presente trabalho, no qual, o Vertimec, em ambas as dosagens avaliadas (30 e $40 \mathrm{~mL}$ ) aplicado diretamente sobre os ácaros, acarretou mortalidade de $100 \%$ na avaliação realizada 1 dia após a aplicação.

Observou-se que o número de ácaros $B$. phoenicis retidos na barreira de cola no bioensaio de ação direta, quantificados em cada tratamento, foi menor do que nos bioensaios de ação residual. Pôdese verificar que a quantidade de ácaros retidos na barreira de cola ao final do bioensaio de ação direta não ultrapassou 5\% do total de ácaros transferidos em nenhum dos tratamentos.

Com relação ao bioensaio de ação residual, em que os ácaros foram transferidos aos 5 dias após a aplicação dos produtos, verificou-se que, 1 
dia após a transferência, o padrão Tricofol diferiu significativamente da testemunha e dos demais produtos à base de abamectina, apresentando percentual de mortalidade de $98 \%$ (Tabela 2). Os tratamentos Acaramik e Vertimec, ambos a 40 $\mathrm{mL}$, diferiram estatisticamente da testemunha e apresentaram percentuais de mortalidade de 39 e $45 \%$, respectivamente. Os demais tratamentos não diferiram estatisticamente da testemunha (Tabela 2).

A partir da segunda avaliação, realizada aos 3 dias após a transferência, todos os tratamentos diferiram da testemunha, com exceção do Abamectin Nortox a $30 \mathrm{~mL}$, que foi semelhante à testemunha em todas as avaliações realizadas. O tratamento Abamectin Nortox a $40 \mathrm{~mL}$ foi semelhante à testemunha nas avaliações realizadas aos 5 e 10 dias após a transferência dos ácaros (Tabela 2). Analisando os resultados obtidos, após 3 dias da transferência, observou-se mortalidade semelhante entre os produtos Acaramik, Vertimec e o tratamentopadrão Tricofol, em todas as dosagens testadas, pois não diferiram estatisticamente entre si.

Em todos os bioensaios, os melhores resultados foram conseguidos com o Tricofol, cujos percentuais de mortalidade variaram de 98 a $100 \%$. Nos demais tratamentos, a porcentagem de mortalidade elevou-se à medida que aumentou o tempo de exposição dos ácaros B. phoenicis ao resíduo dos produtos. Com exceção das dosagens testadas de Abamectin Nortox, todos os tratamentos apresentaram 100\% de mortalidade aos 15 dias após a transferência dos ácaros.

Resultados obtidos em laboratório por Jardim et al. (2008) evidenciaram que a abamectina (produto comercial não informado), na dosagem de 30 mL p.c./100 L de água, apresentou eficiência de $100 \%$ de mortalidade por aplicação direta sobre $B$. phoenicis, aos 11 dias após a aplicação.

No experimento de ação residual, em que os ácaros foram transferidos para os frutos após 10 dias da aplicação dos produtos, pôde-se observar que, na primeira avaliação realizada a 1 dia da transferência, somente o Vertimec e o Abamectin Nortox, ambos a $30 \mathrm{~mL}$, não diferiram estatisticamente da testemunha (Tabela 3). Os tratamentos Vertimec e Abamectin Nortox, ambos a $40 \mathrm{~mL}$, foram semelhantes ao padrão Tricofol na primeira avaliação, em termos de mortalidade de ácaros. Observou-se também, que Acaramik, nas dosagens avaliadas, apresentou percentuais de mortalidade de 43 a 68\% (Tabela 3).

As maiores doses de Vertimec e Abamectin Nortox mostraram-se mais eficientes por ação residual no controle do ácaro $B$. phoenicis. Benvenga et al. (2002), em trabalhos realizados em campo, na cultura do cafeeiro, obtiveram alta eficiência da abamectina na redução populacional de duas espécies de ácaros-praga: B. phoenicis e Oligonychus ilicis (McGregor, 1917).

As mortalidades de ácaros, quando foram transferidos 10 dias após a aplicação, aumentaram gradativamente nas avaliações realizadas aos 3; 5; 10 e 15 dias após a transferência (Tabela 3), semelhantemente ao experimento de ação residual onde os ácaros foram transferidos 5 dias após aplicação dos produtos.

Na primeira avaliação realizada 1 dia após a transferência, em que os ácaros B. phoenicis foram transferidos 15 dias após a aplicação, o número médio de ácaros vivos foi elevado em todos os tratamentos, com exceção do Tricofol, quando comparados com os experimentos de ação residual discutidos anteriormente (Tabela 4). Isto se deve ao maior tempo entre a aplicação dos produtos e a transferência dos ácaros, que provavelmente permitiu maior degradação dos produtos em relação aos experimentos anteriores, reduzindo a eficiência dos mesmos sobre o ácaro da leprose dos citros.

Verificou-se que, na avaliação realizada 1 dia após a transferência dos ácaros, somente os tratamentos com Tricofol e Acaramik a 40 e $50 \mathrm{~mL}$ diferiram da testemunha. O tratamento com Tricofol, assim como nos outros dois experimentos de ação residual, ocasionou mortalidade de $B$. phoenicis mais rápida que os produtos à base de abamectina, diferindo estatisticamente da testemunha e dos demais tratamentos (Tabela 4).

Apesar dos resultados obtidos nesses experimentos pelo tratamento com o Tricofol sobre a mortalidade de $B$. phoenicis, sua utilização deve ser realizada de maneira criteriosa, obedecendo aos princípios propostos pelo manejo da resistência. Inúmeros casos de resistência de ácaros ao dicofol já foram relatadas, porém seu uso continua sendo um importante componente do manejo integrado de pragas em alguns sistemas agrícolas, como citros na Flórida (USA) e no Brasil, macieira em Nova York (USA) e algodoeiro na Califórnia (USA), devido a sua especificidade de ação e custo relativamente baixo (Alves, 1999).

De acordo com Omoto et al. (2000), outro fator relevante que pode justificar a continuidade de utilização do dicofol, está relacionado à alta instabilidade da resistência, ou seja, a constatação da redução significativa na frequência de ácaros resistentes na ausência de pressão de seleção.

No bioensaio em que os ácaros foram trans- 
feridos 15 dias após a aplicação, constatou-se que os produtos agiram mais lentamente na mortalidade do ácaro B. phoenicis, quando comparado aos bioensaios em que os ácaros foram transferidos aos 5 e 10 dias após a aplicação, principalmente na segunda avaliação, realizada aos 3 dias após a transferência, que apresentou, de modo geral, porcentagens de mortalidade inferiores aos demais bioensaios de ação residual.

Na segunda avaliação (3 dias após a transferência dos ácaros), apenas o Acaramik a 20 mL não diferiu da testemunha (Tabela 4). Os tratamentos com Acaramik a 40 e $50 \mathrm{~mL}$ e Vertimec a $40 \mathrm{~mL}$ obtiveram resultados semelhantes ao padrão Tricofol, pois não diferiram estatisticamente entre si.

A partir da terceira avaliação, cinco dias após a transferência dos ácaros, todos os tratamentos diferiram da testemunha. Aos 5 dias após a transferência, os tratamentos Acaramik a 50 mL, Vertimec a 40 mL e Tricofol apresentaram mortalidade de ácaros de $100 \%$ (Tabela 4 ).

Decorridos 15 dias da transferência, todos os tratamentos apresentaram porcentagens de mortalidade superiores a 90\%, com exceção do Vertimec a $30 \mathrm{~mL}$, que apresentou $87 \%$ de mortalidade. Diversos trabalhos, como os de Pattaro (2003), Andrade et al. (2008) e Franco (2007), comprovaram para vários produtos acaricidas, entre eles a abamectina, que a mortalidade é maior à medida que aumenta o período de exposição do acarino ao resíduo do produto.

Com relação ao número de ácaros $B$. phoenicis retidos na barreira de cola, obsevou-se que foi superior nos bioensaios de ação residual, quando comparados ao bioensaio de ação direta. No bioensaio em que os ácaros foram transferidos para os frutos 15 dias após a aplicação, verificou-se a maior quantidade de ácaros retidos na cola em todos os tratamentos, com percentuais que variaram de 16 a 30\%. Nos bioensaios de ação residual, a transferência dos ácaros é realizada após a aplicação dos produtos sobre os frutos, portanto a aplicação não é direta sobre o corpo dos ácaros. Desta forma, admite-se que esta maior fuga de ácaros para a cola, nos bioensaios de ação residual, seja devida a ácaros que não se contaminaram com o ingrediente ativo, ou contaminaram-se com quantidade insuficiente para ocasionar sua morte, acarretando, provavelmente, em repelência à área tratada e irritabilidade destes ácaros, o que resultou em maior fuga de ácaros para a cola.

TABELA 1 - Número médio de ácaros Brevipalpus phoenicis vivos e porcentagem de mortalidade nas avaliações realizadas 1; 3; 5; 10 e 15 dias após a aplicação dos produtos, no experimento de ação direta.

\begin{tabular}{|c|c|c|c|c|c|c|c|c|c|c|}
\hline \multirow{3}{*}{ Tratamentos } & \multicolumn{10}{|c|}{ Dias após a aplicação } \\
\hline & \multicolumn{2}{|c|}{1} & \multicolumn{2}{|c|}{3} & \multicolumn{2}{|c|}{5} & \multicolumn{2}{|c|}{10} & \multicolumn{2}{|c|}{15} \\
\hline & Média & $\begin{array}{c}\% \\
\text { Mort. }\end{array}$ & Média & $\begin{array}{c}\% \\
\text { Mort. }\end{array}$ & Média & $\begin{array}{c}\% \\
\text { Mort. }\end{array}$ & Média & $\begin{array}{c}\% \\
\text { Mort. }\end{array}$ & Média & $\begin{array}{c}\% \\
\text { Mort. }\end{array}$ \\
\hline Acaramik $^{1}$ & $3,2 \mathrm{~b}$ & 62 & $3,0 \mathrm{~b}$ & 65 & $2,8 \mathrm{~b}$ & 76 & $2,3 \mathrm{~b}$ & 99 & $2,2 \mathrm{~b}$ & 100 \\
\hline Acaramik $^{2}$ & $3,2 \mathrm{~b}$ & 68 & $2,6 \mathrm{bc}$ & 86 & $2,5 \mathrm{bc}$ & 92 & $2,2 \mathrm{~b}$ & 100 & $2,2 \mathrm{~b}$ & 100 \\
\hline Acaramik $^{3}$ & $2,5 \mathrm{c}$ & 92 & $2,4 \mathrm{c}$ & 97 & $2,3 \mathrm{c}$ & 97 & $2,2 \mathrm{~b}$ & 100 & $2,2 \mathrm{~b}$ & 100 \\
\hline Acaramik $^{4}$ & $2,2 \mathrm{c}$ & 100 & $2,2 \mathrm{c}$ & 100 & $2,2 \mathrm{c}$ & 100 & $2,2 \mathrm{~b}$ & 100 & $2,2 \mathrm{~b}$ & 100 \\
\hline Vertimec $^{2}$ & $2,2 \mathrm{c}$ & 100 & $2,2 \mathrm{c}$ & 100 & $2,2 \mathrm{c}$ & 100 & $2,2 \mathrm{~b}$ & 100 & $2,2 \mathrm{~b}$ & 100 \\
\hline Vertimec $^{3}$ & $2,3 \mathrm{c}$ & 100 & $2,2 \mathrm{c}$ & 100 & $2,2 \mathrm{c}$ & 100 & $2,2 \mathrm{~b}$ & 100 & $2,2 \mathrm{~b}$ & 100 \\
\hline Abamectin Nortox ${ }^{2}$ & $2,3 \mathrm{c}$ & 100 & $2,2 \mathrm{c}$ & 100 & $2,2 \mathrm{c}$ & 100 & $2,2 \mathrm{~b}$ & 100 & $2,2 \mathrm{~b}$ & 100 \\
\hline Abamectin Nortox ${ }^{3}$ & $2,2 \mathrm{c}$ & 98 & $2,2 \mathrm{c}$ & 100 & $2,2 \mathrm{c}$ & 100 & $2,2 \mathrm{~b}$ & 100 & $2,2 \mathrm{~b}$ & 100 \\
\hline Tricofol $^{5}$ & $2,2 \mathrm{c}$ & 100 & $2,2 \mathrm{c}$ & 100 & $2,2 \mathrm{c}$ & 100 & $2,2 \mathrm{~b}$ & 100 & $2,2 \mathrm{~b}$ & 100 \\
\hline Testemunha & $4,8 \mathrm{a}$ & - & $4,5 \mathrm{a}$ & - & $4,1 \mathrm{a}$ & - & 3,3 a & - & $2,7 \mathrm{a}$ & - \\
\hline TESTE F & \multicolumn{2}{|c|}{$53,54^{* *}$} & \multicolumn{2}{|c|}{$53,72 * *$} & \multicolumn{2}{|c|}{$40,75^{* *}$} & \multicolumn{2}{|c|}{$7,62 * *$} & \multicolumn{2}{|c|}{$5,50 * *$} \\
\hline C. V. (\%) & \multicolumn{2}{|c|}{11,0} & \multicolumn{2}{|c|}{9,9} & \multicolumn{2}{|c|}{10,0} & \multicolumn{2}{|c|}{7,7} & \multicolumn{2}{|c|}{7,7} \\
\hline
\end{tabular}

Médias seguidas por letras iguais na mesma coluna não diferem entre si, pelo teste de Tukey, a 5\% de probabilidade. Para a comparação das médias, os dados originais foram transformados em $\ln (\mathrm{X}+5)$. ** Significativo pelo teste $\mathrm{F}$, a $5 \%$ de probabilidade. ${ }^{1} 20 \mathrm{~mL}$ p.c./100 $\mathrm{L} ;{ }^{2} 30 \mathrm{~mL}$ p.c./100 L; ${ }^{3} 40 \mathrm{~mL}$ p.c./100 L; ${ }^{4} 50 \mathrm{~mL}$ p.c./100 L; ${ }^{5} 77 \mathrm{~mL}$ p.c./100 L. 
TABELA 2 - Número médio de ácaros Brevipalpus phoenicis vivos e porcentagem de mortalidade nas avaliações realizadas $1 ; 3 ; 5 ; 10$ e 15 dias após a transferência, no experimento de ação residual dos produtos (5 dias após a aplicação).

\begin{tabular}{|c|c|c|c|c|c|c|c|c|c|c|}
\hline \multirow{3}{*}{ Tratamentos } & \multicolumn{10}{|c|}{ Dias após a transferência } \\
\hline & \multicolumn{2}{|c|}{1} & \multicolumn{2}{|c|}{3} & \multicolumn{2}{|c|}{5} & \multicolumn{2}{|c|}{10} & \multicolumn{2}{|c|}{15} \\
\hline & Média & $\begin{array}{c}\% \\
\text { Mort. }\end{array}$ & Média & $\begin{array}{c}\% \\
\text { Mort. }\end{array}$ & Média & $\begin{array}{c}\% \\
\text { Mort. }\end{array}$ & Média & $\begin{array}{c}\% \\
\text { Mort. }\end{array}$ & Média & $\begin{array}{c}\% \\
\text { Mort. }\end{array}$ \\
\hline Acaramik $^{1}$ & 4,6 a & 15 & $2,8 \mathrm{c}$ & 81 & $2,3 \mathrm{~b}$ & 99 & $2,2 \mathrm{~b}$ & 99 & $2,2 \mathrm{c}$ & 100 \\
\hline Acaramik $^{2}$ & 4,1 abcd & 26 & $2,3 \mathrm{~cd}$ & 90 & $2,2 \mathrm{~b}$ & 100 & $2,2 \mathrm{~b}$ & 100 & $2,2 \mathrm{c}$ & 100 \\
\hline Acaramik $^{3}$ & $3,7 \mathrm{~cd}$ & 39 & $2,3 \mathrm{~cd}$ & 97 & $2,2 \mathrm{~b}$ & 100 & $2,2 \mathrm{~b}$ & 100 & $2,2 \mathrm{c}$ & 100 \\
\hline Acaramik $^{4}$ & $4,2 \mathrm{abc}$ & 21 & $2,2 \mathrm{~d}$ & 100 & $2,2 \mathrm{~b}$ & 100 & $2,2 \mathrm{~b}$ & 100 & $2,2 \mathrm{c}$ & 100 \\
\hline Vertimec $^{2}$ & 4,0 bcd & 29 & $2,3 \mathrm{~cd}$ & 97 & $2,4 \mathrm{~b}$ & 100 & $2,2 \mathrm{~b}$ & 100 & $2,2 \mathrm{c}$ & 100 \\
\hline Vertimec $^{3}$ & $3,5 \mathrm{~d}$ & 45 & $2,4 \mathrm{~cd}$ & 94 & $2,4 \mathrm{~b}$ & 100 & $2,2 \mathrm{~b}$ & 100 & $2,2 \mathrm{c}$ & 100 \\
\hline Abamectin Nortox ${ }^{2}$ & $4,1 \mathrm{abc}$ & 21 & $4,0 \mathrm{ab}$ & 19 & $3,5 \mathrm{a}$ & 32 & $2,8 \mathrm{ab}$ & 64 & $2,8 \mathrm{ab}$ & 60 \\
\hline Abamectin Nortox ${ }^{3}$ & $4,2 \mathrm{abc}$ & 19 & $3,6 \mathrm{~b}$ & 39 & 3,3 a & 36 & $2,7 \mathrm{ab}$ & 82 & $2,5 \mathrm{bc}$ & 84 \\
\hline Tricofol $^{5}$ & $2,3 \mathrm{e}$ & 98 & $2,3 \mathrm{~cd}$ & 98 & $2,2 \mathrm{~b}$ & 100 & $2,2 \mathrm{~b}$ & 100 & $2,2 \mathrm{c}$ & 100 \\
\hline Testemunha & $4,5 \mathrm{ab}$ & - & $4,2 \mathrm{a}$ & - & $3,8 \mathrm{a}$ & - & $3,2 \mathrm{a}$ & - & $3,0 \mathrm{a}$ & - \\
\hline TESTE F & \multicolumn{2}{|c|}{$23,29 * *$} & \multicolumn{2}{|c|}{$52,12 * *$} & \multicolumn{2}{|c|}{$25,11 * *$} & \multicolumn{2}{|c|}{$8,99 * *$} & \multicolumn{2}{|c|}{$8,53 * *$} \\
\hline C. V. (\%) & \multicolumn{2}{|c|}{9,3} & \multicolumn{2}{|c|}{10,0} & \multicolumn{2}{|c|}{12,2} & \multicolumn{2}{|c|}{14,3} & \multicolumn{2}{|c|}{11,8} \\
\hline
\end{tabular}

Médias seguidas por letras iguais na mesma coluna não diferem entre si, pelo teste de Tukey, a 5\% de probabilidade. Para a comparação das médias, os dados originais foram transformados em $\ln (\mathrm{X}+5)$. ${ }^{* *}$ Significativo pelo teste $\mathrm{F}$, a $5 \%$ de probabilidade. ${ }^{1} 20 \mathrm{~mL}$ p.c./100 L; $230 \mathrm{~mL}$ p.c./100 L; ${ }^{3} 40 \mathrm{~mL}$ p.c./100 L; ${ }^{4} 50 \mathrm{~mL}$ p.c./100 L; ${ }^{5} 77 \mathrm{~mL}$ p.c./100 L.

TABELA 3 - Número médio de ácaros Brevipalpus phoenicis vivos e porcentagem de mortalidade nas avaliações realizadas 1; 3; 5; 10 e 15 dias após a transferência dos ácaros, no experimento de ação residual dos produtos (10 dias após a aplicação).

\begin{tabular}{|c|c|c|c|c|c|c|c|c|c|c|c|}
\hline \multirow{3}{*}{ Tratamentos } & \multicolumn{11}{|c|}{ Dias após a transferência } \\
\hline & \multicolumn{2}{|l|}{1} & \multicolumn{2}{|c|}{3} & \multicolumn{2}{|c|}{5} & \multicolumn{3}{|c|}{10} & \multicolumn{2}{|c|}{15} \\
\hline & Média & & Média & $\begin{array}{c}\% \\
\text { Mort. }\end{array}$ & Média & $\begin{array}{c}\% \\
\text { Mort. }\end{array}$ & Médi & & $\begin{array}{c}\% \\
\text { Mort. }\end{array}$ & $\begin{array}{l}\text { Mé- } \\
\text { dia }\end{array}$ & $\begin{array}{c}\% \\
\text { Mort. }\end{array}$ \\
\hline Acaramik $^{1}$ & 3,6 bcd & 43 & $2,4 \mathrm{~b}$ & 92 & $2,2 \mathrm{~b}$ & 100 & 2,2 & $\mathrm{~b}$ & 100 & $2,2 \mathrm{~b}$ & 100 \\
\hline Acaramik $^{2}$ & $3,5 \mathrm{~cd}$ & 55 & $2,2 \mathrm{~b}$ & 100 & $2,2 \mathrm{~b}$ & 100 & 2,2 & $\mathrm{~b}$ & 100 & $2,2 \mathrm{~b}$ & 100 \\
\hline Acaramik $^{3}$ & $3,1 \mathrm{~d}$ & 70 & $2,3 \mathrm{~b}$ & 99 & $2,2 \mathrm{~b}$ & 100 & 2,2 & $\mathrm{~b}$ & 100 & $2,2 \mathrm{~b}$ & 100 \\
\hline Acaramik ${ }^{4}$ & $3,2 \mathrm{~d}$ & 68 & $2,2 \mathrm{~b}$ & 100 & $2,2 \mathrm{~b}$ & 100 & 2,2 & $\mathrm{~b}$ & 100 & $2,2 \mathrm{~b}$ & 100 \\
\hline Vertimec $^{2}$ & $4,3 \mathrm{abc}$ & 32 & $2,5 \mathrm{~b}$ & 88 & $2,4 \mathrm{~b}$ & 91 & 2,4 & $\mathrm{~b}$ & 100 & $2,2 \mathrm{~b}$ & 100 \\
\hline Vertimec $^{3}$ & 2,9 de & 75 & $2,4 \mathrm{~b}$ & 94 & $2,4 \mathrm{~b}$ & 93 & 2,3 & $\mathrm{~b}$ & 100 & $2,2 \mathrm{~b}$ & 100 \\
\hline Abamectin Nortox ${ }^{2}$ & $4,4 a b$ & 25 & $2,5 b$ & 89 & $2,5 b$ & 87 & 2,5 & b & 64 & $2.3 \mathrm{~b}$ & 100 \\
\hline Abamectin Nortox ${ }^{3}$ & 3,0 de & 70 & $2,3 \mathrm{~b}$ & 98 & $2,2 \mathrm{~b}$ & 100 & 2,2 & $\mathrm{~b}$ & 100 & $2,2 \mathrm{~b}$ & 100 \\
\hline Tricofol $^{5}$ & $2,2 \mathrm{e}$ & 100 & $2,2 \mathrm{~b}$ & 100 & $2,2 \mathrm{~b}$ & 100 & 2,2 & b & 100 & $2,2 \mathrm{~b}$ & 100 \\
\hline Testemunha & 4,9 a & - & 4,5 a & - & $4,2 \mathrm{a}$ & - & 3,7 & $\mathrm{a}$ & - & 3,0 a & - \\
\hline TESTE F & \multicolumn{2}{|c|}{$19,17 * *$} & \multicolumn{2}{|c|}{$52,51 * *$} & \multicolumn{2}{|c|}{$48,95^{* *}$} & \multicolumn{3}{|c|}{$29,46^{* *}$} & \multicolumn{2}{|c|}{$10,17 * *$} \\
\hline C. V. (\%) & \multicolumn{2}{|c|}{13,62} & \multicolumn{2}{|c|}{9,68} & \multicolumn{2}{|c|}{9,66} & \multicolumn{3}{|c|}{9,31} & \multicolumn{2}{|c|}{7,41} \\
\hline
\end{tabular}

Médias seguidas por letras iguais na mesma coluna não diferem entre si, pelo teste de Tukey, a $5 \%$ de probabilidade. Para a comparação das médias, os dados originais foram transformados em $\ln (\mathrm{X}+5)$. ${ }^{* *}$ Significativo pelo teste $\mathrm{F}$, a $5 \%$ de probabilidade. ${ }^{1} 20 \mathrm{~mL}$ p.c. $/ 100 \mathrm{~L}$; ${ }^{2} 30 \mathrm{~mL}$ p.c./100 L; ${ }^{3} 40 \mathrm{~mL}$ p.c./100 L; ${ }^{4} 50 \mathrm{~mL}$ p.c./100 L; ${ }^{5} 77$ mL p.c./100 L. 
TABELA 4 - Número médio de ácaros Brevipalpus phoenicis vivos e porcentagem de mortalidade nas avaliações realizadas 1; 3; 5; 10 e 15 dias após a transferência dos ácaros, no experimento de ação residual das formulações de abamectinas (15 dias após a aplicação).

\begin{tabular}{|c|c|c|c|c|c|c|c|c|c|c|}
\hline \multirow{3}{*}{ Tratamentos } & \multicolumn{10}{|c|}{ Dias após a transferência } \\
\hline & \multicolumn{2}{|l|}{1} & \multicolumn{2}{|c|}{3} & \multicolumn{2}{|c|}{5} & \multicolumn{2}{|c|}{10} & \multicolumn{2}{|c|}{15} \\
\hline & Média & & Média & $\begin{array}{c}\% \\
\text { Mort. }\end{array}$ & Média & $\begin{array}{c}\% \\
\text { Mort. }\end{array}$ & Média & & Média & $\begin{array}{c}\% \\
\text { Mort. }\end{array}$ \\
\hline Acaramik $^{1}$ & $4,5 \mathrm{ab}$ & 43 & $3,8 \mathrm{ab}$ & 37 & 2,5 bc & 84 & $2,5 b$ & 86 & $2,3 \mathrm{~b}$ & 93 \\
\hline Acaramik $^{2}$ & $4,4 \mathrm{ab}$ & 55 & $3,0 \mathrm{bcd}$ & 72 & $2,3 \mathrm{c}$ & 96 & $2,3 \mathrm{~b}$ & 97 & $2,3 \mathrm{~b}$ & 94 \\
\hline Acaramik $^{3}$ & $3,4 \mathrm{c}$ & 70 & 2,5 de & 87 & $2,3 \mathrm{c}$ & 96 & $2,3 \mathrm{~b}$ & 99 & $2,3 \mathrm{~b}$ & 97 \\
\hline Acaramik $^{4}$ & 3,9 bc & 68 & 2,5 de & 91 & $2,2 \mathrm{c}$ & 100 & $2,2 \mathrm{~b}$ & 100 & $2,2 \mathrm{~b}$ & 100 \\
\hline Vertimec $^{2}$ & 4,2 abc & 32 & 3,3 bc & 65 & $2,8 \mathrm{~b}$ & 77 & $2,6 \mathrm{~b}$ & 82 & $2,4 \mathrm{~b}$ & 87 \\
\hline Vertimec $^{3}$ & $4,3 \mathrm{ab}$ & 75 & 2,7 cde & 80 & $2,2 \mathrm{c}$ & 100 & $2,2 \mathrm{~b}$ & 100 & $2,2 \mathrm{~b}$ & 100 \\
\hline Abamectin Nortox ${ }^{2}$ & $4,3 \mathrm{ab}$ & 25 & $3,6 b$ & 47 & $2,3 \mathrm{c}$ & 96 & $2,2 \mathrm{~b}$ & 100 & $2,2 \mathrm{~b}$ & 100 \\
\hline Abamectin Nortox ${ }^{3}$ & 4,3 ab & 70 & $3,6 \mathrm{~b}$ & 45 & $2,2 \mathrm{c}$ & 99 & $2,2 \mathrm{~b}$ & 100 & $2,2 \mathrm{~b}$ & 100 \\
\hline Tricofol $^{5}$ & $2,2 \mathrm{~d}$ & 100 & $2,2 \mathrm{e}$ & 100 & $2,2 \mathrm{c}$ & 100 & $2,2 \mathrm{~b}$ & 100 & $2,2 \mathrm{~b}$ & 100 \\
\hline Testemunha & 4,8 a & - & $4,5 \mathrm{a}$ & - & 4,3 a & - & $3,6 \mathrm{a}$ & - & $3,0 \mathrm{a}$ & - \\
\hline TESTE F & 16,8 & $7 * *$ & 19 & $13^{* *}$ & 69 , & $34 * *$ & 32,0 & $* *$ & 13,3 & \\
\hline C. V. (\%) & 11,7 & & 13 & & 7 & & 8,4 & & 7,1 & \\
\hline
\end{tabular}

Médias seguidas por letras iguais na mesma coluna não diferem entre si, pelo teste de Tukey, a 5\% de probabilidade. Para a comparação das médias, os dados originais foram transformados em $\ln (\mathrm{X}+5)$. $* *$ Significativo pelo teste $\mathrm{F}$, a $5 \%$ de probabilidade. ${ }^{1} 20 \mathrm{~mL}$ p.c. $/ 100 \mathrm{~L} ;{ }^{2} 30 \mathrm{~mL}$ p.c./100 L; ${ }^{3} 40 \mathrm{~mL}$ p.c. $/ 100 \mathrm{~L} ;{ }^{4} 50 \mathrm{~mL}$ p.c./100 L; ${ }^{5} 77 \mathrm{~mL}$ p.c./100 L.

\section{CONCLUSÕES}

Os produtos à base de abamectina: Acaramik a 20; 30; 40 e $50 \mathrm{~mL}$, Vertimec $18 \mathrm{EC}$ a 30 e 40 mL e Abamectin Nortox a $40 \mathrm{~mL}$, todos por $100 \mathrm{~L}$ de água, são eficientes no controle do ácaro B. phoenicis com eficiências semelhantes ao padrão Tricofol a 77 mL/100 L de água.

\section{REFERÊNCIAS}

ABBOTT, W.S. A method of computing the effectiveness of an insecticide. Journal of Economic Entomology, London, v.18, p.265-267, 1925.

ALBUQUERQUE, F.A.; OLIVEIRA, C.A.L. de; BARRETO, M. Estudos da relação entre as incidências de verrugose da laranja-doce e leprose dos citros em frutos de laranja-pera. Científica, São Paulo, v.25, n.2, p.393-402. 1997.

ALVES, E.B.; OMOTO, C.; FRANCO, C.R. Resistência cruzada entre o dicofol e outros acaricidas em Brevipalpus phoenicis (Geijskes) (Acari: Tenuipalpidae). Anais da Sociedade Entomológica do Brasil, Londrina, v.29, n.4, p.765-771, 2000.
ANDRADE, D.J.; OLIVEIRA, C.A.L.de; PATTARO, F.C. Avaliação da eficiência de acaricidas, por ação direta e residual, sobre Tetranychus mexicanus (McGregor, 1950) (Acari: Tetranychidae) em citros. Revista de Agricultura, Piracicaba, v.83, n.1, p.2834, 2008.

BENVENGA, S.R.; GRAVENA, S.; CAETANO, A.C.; SILVA, J.L.; LINARDI, M.S.; ARAÚJO JÚNIOR, N. Manejo de Leucoptera coffeela, Brevipalpus phoenicis e Oligonychus ilicis com abamectin e emamectin e sua influência sobre inimigos naturais em cafeeiro. In: CONGRESSO BRASILEIRO DE ENTOMOLOGIA, 19., 2002, Manaus. Resumos... Manaus: Sociedade Entomológica do Brasil, 2002. p.272.

CHIAVEGATO, L.G.; MISCHAN, N.M.; SILVA, M.A. Prejuízos e transmissibilidade de sintomas de leprose pelo ácaro Brevipalpus phoenicis (Geijskes, 1939) (Acari: Tenuipalpidae) em citros. Científica, Jaboticabal, v.10, n.2, p.265-271, 1982.

FERNANDES, A.P.; OLIVEIRA, C.A.L. de; FERREIRA, M.C. Eficiência de acaricidas sobre populações de Brevipalpus phoenicis (Geijskes) 
(Acari Tenuipalpidae) de citros e cafeeiro. Revista de Agricultura, Piracicaba, v.83, n.1, p.45-55, 2008.

FRANCESCHI, G.P.; NETO, J.G.; ARANTES, S.O.; MADEIRA, J.A.P.; ANAKELY ALVES REZENDE, A.A. Estudo da praticabilidade e eficácia agronômica do produto abamectin nortox (abamectina), no controle do ácaro-da-mancha-anular Brevipalpus phoenicis (Geijskes) na cultura do café (Coffea arabica). In: CONGRESSO BRASILEIRO DE ENTOMOLOGIA, 22, 2008, Uberlândia. Resumos... Uberlândia: Sociedade Entomológica do Brasil, 2008. CD-ROM.

FRANCO, C.R.; CASARIN, N.F.B.; DOMINGUES, F.A.; OMOTO, C. Resistência de Brevipalpus phoenicis (Geijskes) (Acari: Tenuipalpidae) a acaricidas inibidores da respiração celular em citros: resistência cruzada e custo adaptativo. Neotropical Entomology, Londrina, v.36, n.4, p.565-576, 2007.

GALLO, D.; NAKANO, O.; NETO, S.S.; CARVALHO, R.P.L.; BAPTISTA, G.C.; FILHO, E.B.; PARRA, J.R.P.; ZUCCHI, R.A.; ALVES, S.B.; VENDRAMIM, J.D.; MARCHINI, L.C.; LOPES, J.R.S.; OMOTO, C. Entomologia agrícola. 10.ed. Piracicaba: FEALQ, 2002. 920p.

JARDIM, J.; PRADO, E.P.; DAL POGETTO, M.H.F.A.; AGUIAR JÚNIOR, H.O.; CHRISTOVAM, R.S.; RAETANO, C.G. Controle químico do ácaroda-leprose, Brevipalpus phoenicis, nos citros em condições de laboratório. In: CONGRESSO BRASILEIRO DE ENTOMOLOGIA, 22., 2008, Uberlândia. Resumos... Uberlândia, Sociedade Entomológica do Brasil, 2008. CD-ROM.
OLIVEIRA, C.A.L.de. Flutuação populacional e medidas de controle do ácaro da leprose Brevipalpus phoenicis (Geijskes, 1939) em citros. Laranja, Cordeirópolis, v.7, n.1, p.1-31, 1986.

OLIVEIRA, C.A.L. de; SANTOS, J.R.; SALA, I. Ácaro da leprose dos citros: resultados de 104 ensaios de campo visando a seu controle, 1985-1990. Jaboticabal: FUNEP, 1991. 56p.

OMOTO, C.; ALVES, E.B.; RIBEIRO, P.C. Detecção e monitoramento da resistência de Brevipalpus phoenicis (Geijskes, 1939) (Acari: Tenuipalpidae) ao dicofol. Anais da Sociedade Entomológica do Brasil, Jaboticabal, v.29, n.4, p.757-764, 2000.

PATTARO, F.C. Calda sulfocálcica no agrossistema citrícola. 2003. 73 f. Dissertação (Mestrado em Agronomia) - Faculdade de Ciências Agrárias e Veterinárias, Universidade Estadual Paulista, Jaboticabal, 2003.

REIS, P. R.; NETO, M.P.; FRANCO, R.A.; TEODORO, A.V. Controle de Brevipalpus phoenicis (Geijskes, 1939) e Oligonychus ilicis (MCgregor, 1917) (acari: Tenuipalpidae, Tetranychidae) em cafeeiro e o impacto sobre ácaros benéficos. I - abamectin e emamectin. Ciência e Agrotecnologia, Lavras, v.28, n.2, p.269-281, 2004.

RODRIGUES, J.C.V.; CHILDERS, C.C.; KITAJIMA, E.W.; MACHADO, M.A.; NOGUEIRA, N.L. Uma nova estratégia para o controle da leprose dos citros. Laranja, Cordeirópolis, v.22, n.2, p.441-423, 2001. 